\title{
MAIS UMA VEZ OUESTIONA-SE: E O IMPACTO DA PESQUISA NA PRÁTICA DA ENFERMAGEM?
}

Atualmente, aárea da Enfermagem, no CNPq, tem 167 bolsistas de produtividade em pesquisa; na CAPES, são 67 Programas, com 33 cursos de doutorado, 50 de mestrado acadêmico e 15 de mestrado profissional ${ }^{(1)}$. No triênio 2010-2012, esses Programas relataram à CAPES a publicação de 9.206 artigos, sendo 2.787 em periódicos Qualis A, ocupando o sexto lugar em produção na área, superados apenas pelos Estados Unidos, Reino Unido, Austrália, França e Canadá(2). Assim, temos muito a comemorar e do que nos orgulhar quanto ao crescimento e desenvolvimento da Enfermagem, especialmente, quanto aos avanços na formação de recursos humanos e produção científica.

Acreditamos e defendemos que qualificação profissional e produção de conhecimentos na enfermagem são relevantes estratégias para avanços e qualificação da prática de enfermagem. Acreditamos, do mesmo modo, que a dimensão ética na produção do conhecimento remete à autonomia do pesquisador, na definição do problema de pesquisa, na necessária socialização dos achados e na sua incorporação à prática profissional.

Parece pertinente, entretanto, voltarmos a questionar se os conhecimentos produzidos e socializados têm contribuido para transformar a realidade? Qual seu impacto para a prática do cuidado de enfermagem e de saúde? Parece pertinente, ainda, perguntarmo-nos se, realmente, consideramos importante que a qualificação de enfermeiros como mestres e doutores, assim como os conhecimentos produzidos e divulgados, repercutam, positivamente, na atuação profissional da Enfermagem. Sabemos a resposta dessa questão que, há anos, nos inquieta, instiga e, podemos, dizer, também, frustra-nos.

Considerando nosso crescente fortalecimento acadêmico, mais do que nos questionarmos e problematizarmos acerca do impacto de tais avanços para a realidade, para prática e qualificação do cuidado e da assistência de saúde, parece fundamental e urgente que a área, representada por suas diferentes organizações, instituições e profissionais, consiga avançar nesse propósito: de um patamar de intenções para uma dimensão estratégica,em direção às mudanças e transformações necessárias e cientificamente sustentadas na realidade, numa aproximação com o que Morin denomina de ecologia da ação(3).

Nossas boas intenções, relativas à incorporação do conhecimento produzido à prática, não mais são suficientes; "não vale mais uma ética de intenções. É necessária uma ética que combine intenção e realidade", exigindo não somente a construção de estratégias para percorrer o "caminho necessário", mas de

\author{
Valéria Lerch Lunardi \\ Editora associada \\ Pesquisadora $\mathrm{CNPq}$
}

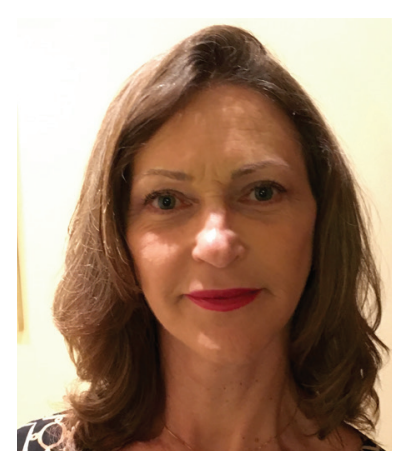

vigilância quanto ao que pensamos e fazemos nesse caminho

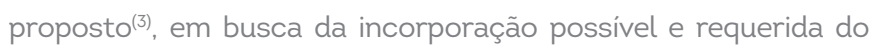
conhecimento produzido à prática.

Nesse sentido, para enfrentar esse problema, que entendemos como complexo, convidarmo-nos a um pensar complexo, contextualizado e integrado, reformando, se necessário, nosso modo de pensar, pode contribuir para religar aparentes diversidades,fragmentações e vazios, reconhecer o permanente jogo dialógico presente entre ordem e desordem, trabalhar nas e com incertezas ${ }^{(4)}$. Por sua vez, a responsabilidade e a solidariedade, como dimensões inseparáveis para uma ação ética, despontam como fundamentais(3), seja em uma necessária mobilização coletiva para a proposição de estratégias, seja na implementação e avaliação das ações estratégicas adotadas para transformar a realidade e qualificar a prática da enfermagem, a partir da sua produção de conhecimento.

\section{REFERÊNCIAS:}

1. Coordenação de Aperfeiçoamento de Pessoal de Nível Superior [Internet]. Brasilia: CAPES; 2015. [acesso 07 out 2015]. Disponivel em:http://www.capes.gov.br.

2.Scochi CGS, Munari DB, Gelbcke FL et al. Relatório de avaliação 2010-2012: área de enfermagem. Coordenação de Aperfeiçoamento de Pessoal de Nível Superior - CAPES, 2013. $62 p$.

3. Morin E. Os sete saberes necessários à educação do presente. In: Moraes MC, Almeida MC. Os setes saberes necessários à educação do presente por uma educação transformadora. Rio de Janeiro:Wak Editora; 2012. P. 33-45.

4. Morin E. Educação e complexidade: os sete saberes e outros ensaios. 6.ed. São Paulo: Cortez, 2013. 